\title{
Os PlanMobs têm contemplado o transporte urbano de carga?
}

\author{
Are PlanMobs considering urban freight transport?
}

\author{
José Maria Diass ${ }^{1}$, José Geraldo Vidal Vieira², João Eduardo A. R. da Silva ${ }^{3}$, Leise Kelli de Oliveira ${ }^{4}$ \\ ${ }^{1}$ Universidade Federal de São Carlos, São Paulo - Brasil, jmdiassor@gmail.com \\ 2Universidade Federal de São Carlos, São Paulo - Brasil, jose-vidal@ufscar.br \\ 3Universidade Federal de São Carlos, São Paulo - Brasil, jesilva@ufscar.br \\ ${ }^{4}$ Universidade Federal de Minas Gerais, Minas Gerais - Brasil, leise@etg.ufmg.br
}

\section{Recebido: \\ 14 de novembro de 2018 \\ Aceito para publicação: \\ 8 de maio de 2020 \\ Publicado: \\ 31 de agosto de 2020 \\ Editor de área: \\ Marcio D'Agosto}

\section{Palavras-chaves:}

Transporte urbano de mercadorias. Logística urbana.

Plano de mobilidade urbana.

Análise de conteúdo.

Survey.

\section{Keywords:}

Urban logistics.

National urban mobility plan.

Urban cargo transport.

DOI:10.14295/transportes.v28i3.1887

\begin{abstract}
RESUMO
A Política Nacional de Mobilidade Urbana regulamenta a acessibilidade e a mobilidade de pessoas e mercadorias nos centros urbanos. No entanto, os gestores públicos aparentam conferir menor importância ao transporte urbano de carga (TUC) em comparação ao transporte público de passageiros. Nesse sentido, esse artigo tem por objetivo investigar se os Planos de Mobilidade Urbana (PlanMobs) têm incorporado a gestão do TUC. Para tanto, foi conduzida uma pesquisa tipo survey com os gestores públicos para identificar a importância do TUC para a mobilidade urbana, bem como analisar os conteúdos dos PlanMobs com referência ao TUC por meio da técnica 'Análise de Conteúdo'. Os resultados mostram que a mobilidade da carga está sendo contemplada de forma superficial nos PlanMobs e, de certa forma, negligenciada pelos gestores públicos.
\end{abstract}

\section{ABSTRACT}

The National Policy of Urban Mobility regulates the accessibility and the mobility of people and goods in urban centers. However, public managers have neglected the management of urban freight transport (UFT) and focused only on the mobility of people. This paper aims to investigate whether the Urban Mobility Plans (UMP) have taken into account the urban freight transport management. As such, a survey was conducted with public managers to identify this importance, as well as the contents of the UMP with reference to UFT though Content Analysis technique. The results show that the freight mobility is being considered superficially within PlanMobs and, somehow neglected by the public managers.

\section{OPEN 2 ACcess

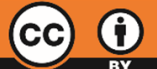

\section{INTRODUÇÃO}

Segundo o IBGE (2010), 84,35\% da população brasileira vive em áreas urbanas, enquanto estudos do UN-Habitat (2013) estimam que a população urbana no Brasil atinja $90 \%$ até 2040. Adicionalmente, a frota de veículos passou de 70.543 .535 (dez/2011) para 104.784.374 (dez/2019), correspondendo a um aumento de 49\% (Denatran, 2019), com uma relação de 2,01 habitantes/veículo (considerando as estimativas da população para 2019 do IBGE). Essa conjuntura e a limitação do espaço urbano (Oliveira e Guerra, 2014) conduzem à utilização intensiva da infraestrutura de transportes, que em geral é pouco planejada, contribuindo ainda mais para reduzir a mobilidade urbana. Para Lakshmanan (2011), a infraestrutura de transportes e o aumento da acessibilidade são fatores críticos de sucesso para o 
desenvolvimento regional. Portanto, a eficiência no transporte urbano, de cargas e de passageiros, é essencial para o bom funcionamento da rede de transporte, importante para a economia e para a satisfação das necessidades da população (Lindholm, 2012).

Para melhorar a acessibilidade e a mobilidade de pessoas e mercadorias, foi instituída no Brasil a Política Nacional de Mobilidade Urbana (PNMU) através da Lei n 12.587/2012 (Brasil, 2012). A lei previa a formalização de um Plano de Mobilidade Urbana (PlanMob) para os municípios com mais de 20.000 habitantes. Inicialmente, a elaboração dos PlanMobs deveria ocorrer até 2015, prazo que foi estendido para 2019 pela Medida Provisória n 818/2018 (Brasil, 2018) e novamente para 2025 pela Lei $n^{\circ} 13.683 / 2018$ (Brasil, 2018b). O PlanMob é o instrumento de efetivação da PNMU e que deve contemplar, além do transporte de passageiros, a operação e a regulação do transporte de cargas na infraestrutura viária dos centros urbanos.

Contudo, as políticas para o TUC não são desenvolvidas da mesma forma que o transporte de passageiros e existe falta de informações sobre o TUC, resultando em uma visão limitada das autoridades públicas sobre seus padrões operacionais, quando tentam desenvolver estratégias (Cherrett et al., 2012).

Nesse contexto, este artigo tem por objetivo investigar se os Planos de Mobilidade Urbana (PlanMobs) têm incorporado a gestão de transporte de carga. Para atingir este objetivo, as soluções de logística urbana (LU) foram analisadas sob ponto de vista dos gestores públicos, identificando as cidades que consideraram tais soluções nos PlanMobs. Pesquisa semelhante foi conduzida por Dias et al. (2018), porém, com foco na percepção dos agentes públicos com relação à implantação de soluções para a logística urbana, independente da existência dos PlanMobs. Adicionalmente, nesse artigo é apresentada uma análise de conteúdo dos PlanMobs quanto ao grau de adoção da gestão do transporte de carga e uma comparação das soluções de logística urbana e das percepções dos agentes públicos quanto ao TUC, comparando as cidades com PlanMob com aquelas que ainda não o têm.

Silva e Marins (2014) apontam falta de estudos sobre a incorporação das soluções de logística urbana nos PlanMobs. Nesse sentido, este artigo contribui com a literatura científica no sentido de analisar como o TUC está sendo contemplado no conteúdo dos planos de mobilidade das cidades brasileiras. Ainda, os resultados apresentados neste artigo comprovam que as cidades têm adotado medidas restritivas, usuais ao tráfego de veículos de carga, independentemente da existência de planos de mobilidade, do porte da cidade e da necessidade de tal medida para a melhoria da mobilidade e acessibilidade da carga. A análise do conteúdo dos PlanMobs revela pouca evolução no gerenciamento do TUC pelas cidades brasileiras, parecendo ser uma mera formalização burocrática para atendimento da Lei $n^{\circ} 12.587 / 2012$. Portanto, torna-se evidente que o transporte de mercadorias não recebe a mesma atenção que a mobilidade de passageiro, conforme afirmação de Lindholm e Blinge (2014).

0 artigo está estruturado em cinco seções, incluindo esta seção introdutória. Na seção 2 é apresentado como ocorre o planejamento do TUC. A metodologia é apresentada na seção 3 e os resultados na seção 4.0 artigo finaliza na seção 5 com as conclusões e as lições aprendidas.

\section{PLANEJAMENTO DO TRANSPORTE URBANO DE CARGA}

As autoridades públicas são os agentes responsáveis por planejar, organizar, controlar e melhorar as soluções relacionadas ao TUC (Taniguchi et al., 2014). Para alcançar a sustentabilidade do TUC, novos modelos de gestão são necessários para que tais agentes desempenhem um papel proativo. 
Wolfram e Consult (2004) enumeram um conjunto de princípios para o planejamento do TUC, a saber:

- A existência de uma estratégia de TUC, que deve ser incorporada em uma estratégia de desenvolvimento global sustentável, com uma perspectiva de longo prazo (20 a 30 anos);

- A definição de um conjunto, "aglomerado urbano", como área de planejamento de transportes e a definição de responsabilidades para os envolvidos no TUC;

- Consulta das partes interessadas para garantir o máximo de transparência durante todo o processo e para melhorar a qualidade, a aceitação, a efetividade e a legitimidade das ações;

- Cooperação dos atores e coordenação de políticas, para assegurar a integração entre os modos de transporte e setores políticos, bem como a cobertura geográfica de toda a aglomeração urbana funcional; e

- Reforço das competências, a fim de garantir que as pessoas chaves (autoridades locais) tenham as habilidades necessárias.

Para Lindholm e Behrends (2012), existem fatores externos que podem ser tanto barreiras como motivadores do planejamento do TUC para se atingir a sua sustentabilidade. Tais fatores podem ser agrupados em quatro categorias principais: (1) fatores institucionais e legais, (2) fatores financeiros, (3) fatores políticos e culturais e (4) fatores práticos e tecnológicos. Os mesmos autores ainda ressaltam que é necessário um plano integrado para a gestão destes fatores complexos, integrando o transporte de carga ao transporte de passageiros. Além disso, reconhece-se que o processo de planejamento do TUC tem um elevado grau de incerteza pelo grande número de potenciais conjuntos de políticas, pelo método de execução, pela resposta dos usuários para cada um desses conjuntos de políticas (Quak, 2011) e pelas respostas das partes interessadas em TUC para o conjunto de políticas (Ballantyne, Lindnholm e Whiteing, 2013).

Apesar disto, as políticas públicas para o TUC devem ter como objetivo melhorar a operação urbana por meio de medidas que reduzam a emissão de poluentes, minimizar a interferência entre o transporte de passageiros e de carga durante os horários de pico, garantir padrões de habitabilidade dentro do ambiente urbano, e manter o bom funcionamento e desenvolvimento da cidade (Gatta e Marcucci, 2014). Para tanto, o TUC deve ser discutido e inserido no planejamento estratégico das cidades (Kiba-Janiak, 2017). Contudo, um grande número de cidades ainda mantém políticas desatualizadas para este setor (Dablanc, 2007). Mesmo em cidades europeias, em que o TUC recebe maior atenção de pesquisadores, existe uma lacuna entre o processo de planejamento e a implementação de medidas para o TUC (Kiba-Janiak, 2017), deixando evidente a falta de políticas públicas que incluam a mobilidade e a acessibilidade de pessoas e mercadorias no planejamento urbano e de transporte. Kiba-Janiak (2017) analisou o escopo dos projetos de TUC implementados em 12 capitais europeias, identificando que poucas cidades têm um nível de maturidade avançado em relação ao assunto. Uma das principais barreiras para a inclusão do TUC nos planos de mobilidade pode estar atrelada à falta de envolvimento dos stakeholders no processo de planejamento e implementação (Ballantyne et al., 2013; Lindholm e Browne, 2014; Lindholm e Ballantyne, 2016). Este planejamento deve considerar a identificação dos problemas, necessidades e soluções (Lindholm e Ballantyne, 2016). Por fim, a inclusão da sustentabilidade da mobilidade urbana é outro fator que precisa ser considerado no processo de planejamento do TUC, em alinhamento aos objetivos de desenvolvimento sustentável 
estipulados pela ONU. A título de exemplo do conflito entre o planejamento do TUC e a sustentabilidade, sabe-se que a operação do TUC em cidades brasileiras é majoritariamente realizada por caminhões, um dos modos de transporte mais poluentes, sem uma gestão eficiente desta operação.

Lindholm e Ballantyne (2016) sugerem alternativas para os planejadores urbanos abordarem melhor o TUC no planejamento de transporte. Inicialmente, o governo precisa estar consciente da importância do TUC para o desenvolvimento econômico. Em segundo lugar, existe a necessidade de um planejamento amplo que auxilie as autoridades locais a identificar as ações necessárias. Além disso, a falta de compreensão do problema pode levar à sub-otimização da medida ou política implementada. No entanto, não existe uma política única que possa atender a todas as demandas e características do TUC, uma vez que a natureza dos problemas varia significativamente de local para local. Além disso, ferramentas e metodologias para implantação/controle do TUC precisam ser continuamente desenvolvidas e melhoradas (Anand et al., 2012). Contudo, embora os resultados da análise sejam uma fonte de dados para ajudar na compreensão das possibilidades, a decisão final de implantação de um plano de forma eficiente ainda está nas mãos dos tomadores de decisão e requer força política para tal implantação (Lindholm e Ballantyne, 2016).

Taniguchi e Thompson (2015) apresentam um conjunto de atividades que devem ser gerenciadas pela administração local para um melhor planejamento e desempenho do TUC para ampliar o fluxo de mercadorias e reduzir externalidades associadas à atividade (como congestionamentos, ruídos, acidentes e poluição). Tais atividades são denominadas soluções de logística urbana. Logística urbana é definida como o processo de otimização das atividades de logística e transporte realizadas por empresas em áreas urbanas, considerando o ambiente de trânsito, o congestionamento e a economia de energia, em uma estrutura de economia de mercado com a utilização de sistemas avançados de informação (Taniguchi e Thompson, 2015; Oliveira et al., 2019). Desta forma, soluções de logística urbana podem ser entendidas como um conjunto de ações que reduzem as externalidades do TUC, com foco na mobilidade urbana sustentável.

Lindholm (2013) sintetiza as soluções de logística urbana em três categorias: infraestrutura, restrições e consolidação. Como a "infraestrutura" da área urbana é onerosa e difícil de alterar, o foco maior das soluções dessa categoria está em utilizar a infraestrutura existente com a maior eficiência possível. Como exemplo, tem-se a utilização da infraestrutura do transporte público de passageiros compartilhada com o transporte de carga e a melhoria das áreas para carga e descarga. As "restrições" estão associadas à limitação de acesso de veículos de carga em determinadas vias ou locais de uma área urbana (Lidholm, 2013). Bontempo et al. (2014) apontam que as restrições à circulação de veículos de carga estão se tornando cada vez mais frequentes nas cidades brasileiras, geralmente nos centros das cidades, durante as horas de pico, e para veículos de maior porte. Bontempo et al. (2014) identificaram 38 cidades brasileiras com população superior a 235 mil habitantes e com restrição à circulação de caminhões. Por fim, a "consolidação" se refere a uma área específica em que as cargas são consolidadas para entrega em um único veículo em vez de todos os destinatários receberem as entregas diretamente dos diferentes expedidores. Em geral, o local de consolidação é denominado de centro de consolidação urbano, micro terminal, centro de distribuição urbana, centro logístico ou terminal urbano. Quak (2008) considera que a consolidação altera a infraestrutura física utilizada pelo TUC. Oliveira e Oliveira (2017) identificaram opiniões divergentes em relação à utilização de um centro de distribuição urbana: os transportadores consideram vantajoso devido à redução 
da distância percorrida e do tempo de operação; os varejistas julgam o nível de eficiência muito baixo enquanto as autoridades locais o consideram eficiente. Apesar disto, os resultados de Carvalho et al. (2019) para Ouro Preto indicam que a consolidação de cargas contribui para a melhora do nível de serviço e prosperidade local (competitividade econômica em termos de rendimentos e níveis de emprego gerados).

Taniguchi e Thompson (2015) sintetizam as soluções de logística urbana em medidas de "gestão do tráfego", "melhorias no modo de transporte", "harmonia com o plano diretor", e "outros". Na Tabela 1 são apresentadas as soluções de logística urbana consideradas na abordagem metodológica deste artigo.

Tabela 1 - Classificação das soluções de logística urbana

\begin{tabular}{|c|c|c|}
\hline Tipo de Gestão & Método de Gestão & Soluções de Logística Urbana \\
\hline \multirow[t]{15}{*}{ Gestão de tráfego } & Gestão de fluxo de trânsito & Construção de anel viário \\
\hline & & Rota para veículos de carga \\
\hline & & Controle de acesso nas cidades \\
\hline & & Zona de baixa emissão \\
\hline & & $\begin{array}{l}\text { Fornecimento de informação de tráfego utilizando Sistema Inteli- } \\
\text { gente de Trânsito }\end{array}$ \\
\hline & Gestão de estacionamento & Estacionamento exclusivo para veículos de carga \\
\hline & & Áreas de carga e descarga na via pública \\
\hline & & $\begin{array}{l}\text { Fornecimento de informação de estacionamento utilizando Sis- } \\
\text { tema Inteligente de Trânsito }\end{array}$ \\
\hline & Gestão de horário & Entrega noturna \\
\hline & & Janela de tempo para entrar nas cidades \\
\hline & & Horário compartilhado entre veículos de carga e carros \\
\hline & Gestão de veículos & Veículos de baixa emissão de poluentes \\
\hline & & Otimização de rotas e escalas \\
\hline & & Pedágio Urbano \\
\hline & & Controle de fator de carregamento \\
\hline \multirow{3}{*}{$\begin{array}{l}\text { Melhoria no método de } \\
\text { transporte }\end{array}$} & Transporte cooperativo & Centros Urbanos de Consolidação \\
\hline & Transporte intermodal & Terminais intermodais \\
\hline & $\begin{array}{l}\text { Co-modalidade do transporte } \\
\text { de carga }\end{array}$ & $\begin{array}{l}\text { Pick-up Points } \\
\text { Veículos elétricos }\end{array}$ \\
\hline $\begin{array}{l}\text { Harmonia com plano } \\
\text { diretor }\end{array}$ & Planejamento do uso do solo & Restrições para localização de instalações logísticas \\
\hline \multirow[t]{4}{*}{ Outros } & Reconhecimento & Reconhecimento de transportadores com selo verde \\
\hline & Sistemas inovadores & Sistema de transporte de cargas subterrâneo \\
\hline & $\begin{array}{l}\text { Melhoria do código de cons- } \\
\text { trução }\end{array}$ & $\begin{array}{l}\text { Avaliação do tamanho de caminhões e estacionamento no código } \\
\text { de construção }\end{array}$ \\
\hline & Organização & Parcerias de qualidade de transporte de cargas \\
\hline
\end{tabular}

Observa-se que a maioria das medidas são de gestão de tráfego, que inclui a gestão do fluxo de trânsito, de estacionamento, de horário e de veículos. As soluções que focam na melhoria no modo de transporte incluem a intermodalidade e a cooperação entre os stakeholders na distribuição urbana. A restrição de instalações logísticas em determinadas regiões de uma cidade é uma solução a ser considerada em consonância com o plano diretor. Por fim, o reconhecimento da eficiência dos operadores logísticos (em termos operacionais e com baixa emissão de carbono) e parcerias de qualidade do TUC estão enquadradas em outros tipos de soluções de logística urbana. A combinação destas soluções pode garantir eficiência e eficácia para o transporte urbano de mercadorias, redução da emissão dos gases de efeito estufa e a consequente melhoria da qualidade de vida dos residentes. 


\section{METODOLOGIA DE PESQUISA}

A metodologia de pesquisa é composta de duas partes. Inicialmente, foi conduzida uma pesquisa tipo survey com os gestores responsáveis pela elaboração/implementação dos PlanMobs nas cidades brasileiras para identificar as práticas de logística urbana adotadas e a percepção desses gestores quanto à importância da gestão de transporte de carga em relação ao transporte público de pessoas. Posteriormente, foi realizada uma pesquisa documental nos planos elaborados pelas cidades a fim de verificar se o transporte de carga está sendo contemplado nesses planos. Essas etapas estão detalhadas nas próximas subseções.

\subsection{Pesquisa de levantamento tipo survey com gestores públicos: amostra e população}

A pesquisa tipo survey foi realizada a partir da revisão de literatura a respeito das soluções de logística urbana adotadas pelas cidades brasileiras. Um questionário foi desenvolvido com o objetivo de obter dados sobre a adoção das soluções de logística urbana pelas cidades, distribuídas em diversas classes de tamanho, independentemente se estas cidades adotavam ou não o PlanMob. Além disso, o questionário procurou obter a percepção dos agentes públicos a respeito do TUC.

A unidade de análise correspondeu às cidades brasileiras com mais de 20 mil habitantes. Para identificação das cidades, utilizou-se das informações de Lima Neto e Galindo (2013), que indicaram 1.650 cidades, pelos seus portes populacionais, obrigadas a elaborarem seus PlanMobs, conforme prevê a PNMU. A amostra calculada consistiu em 230 cidades, com um erro amostral de 6\% e nível de confiança de 95\%.

A coleta de dados ocorreu no período entre 2016 e 2017, através de um questionário eletrônico estruturado. 0 link da pesquisa foi encaminhado aos municípios da amostra selecionada (Portal da cidade na Web ou e-mails), com suporte da Lei de Acesso à Informação (Brasil, 2011). Foram obtidas respostas de 74 cidades. Destas, 25 cidades ainda não tinham plano ou estavam em elaboração e 49 cidades elaboraram os seus PlanMobs, aprovados ou não por suas câmaras municipais. Assim, a amostra foi dividida em dois grupos (cidades com e sem PlanMob) de forma que foi possível realizar análises comparativas entre esses dois grupos.

Inicialmente fez-se uma depuração dos dados, para identificar erros de preenchimento do questionário. Com os questionários validados, estimou-se a confiabilidade das respostas através do coeficiente alfa de Cronbach (Da Hora, Monteiro e Arica, 2010; Hair et al., 2005).

Considerando as respostas válidas, procedeu-se a análise estatística descritiva dos dados, por meio da mediana e quartis. Estas análises permitiram identificar a importância das medidas considerando a opinião dos agentes públicos. Além disso, foi feita uma análise de frequência para identificar quais soluções de logística urbana são mais adotadas pelas cidades, que possuíam ou não PlanMobs. Nestas análises foi utilizado o pacote Microsoft Excel, v.2010.

\subsection{Pesquisa documental}

A pesquisa documental foi feita considerando a população de 174 cidades brasileiras que elaboraram o PlanMob, segundo a pesquisa "Levantamento sobre a situação dos Planos de Mobilidade Urbana nos municípios brasileiros" (MCidades, 2016). Para a seleção, o resultado da amostra calculado foi de 106 cidades, considerando um erro amostral de 6\% e nível de confiança de $95 \%$.

A obtenção dos PlanMobs ocorreu entre setembro de 2016 e dezembro de 2017 por solicitação direta aos órgãos responsáveis de cada prefeitura, por meio do acesso direto onde estavam 
disponíveis os PlanMobs dos municípios e do uso da Lei de Acesso a Informação. Utilizando esse procedimento, foram obtidos PlanMobs de apenas 39 cidades, representando cerca de $13 \%$ da população brasileira. As cidades que tiveram os PlanMobs analisados foram: Ipojuca (PE), Andradina (SP), Aracruz (ES), Belo Horizonte (MG), Bento Gonçalves (RS), Brasília (DF), Cambé (SP), Campo Grande (MS), Capivari (SP), Caraguatatuba (SP), Contagem (MG), Corumbá (MS), Curitiba (PR), Guarapari (ES), Itanhaém (SP), Itapecerica da Serra (SP), Joinville (SC), Juiz de Fora (MG), Linhares (ES), Macaé (RJ), Manaus (AM), Mogi das Cruzes (SP), Mogi Guaçu (SP), Osasco (SP), Pindamonhangaba (SP), Registro (SP), Ribeirão Preto (SP), Salto de Pirapora (SP), Santa Maria (RS), Santa Rosa (SP), São José do Rio Preto (SP), São José dos Campos (SP), São Luiz Gonzaga (RS), São Paulo (SP), Serra (ES), Sorocaba (SP), Tupã (SP), Venâncio Aires (RS).

Apesar do número de cidades com PlanMobs ( $\mathrm{N}=39$ ) ficar abaixo da amostra pretendida, pode-se dizer que a amostra coletada é representativa para a região Sudeste. Em 2018, de 193 cidades (representando $25 \%$ da população brasileira) que declararam ter elaborado o PlanMob, 160 delas (83\%) estão na região Sudeste, sendo a maioria no Estado de São Paulo. Na amostra coletada, 19 cidades (ou 27,5\%) estão nesse Estado. Essas cidades, ainda, representam cerca de 64\% das cidades com mais de 250.000 habitantes que, conforme o roteiro de implantação dos PlanMobs Brasil (2015; p. 220-221), deveriam incorporar o TUC no plano de mobilidade. Pelo seu porte e complexidade de gestão do TUC, acredita-se que os PlanMobs destas cidades serviriam de referência para o desenvolvimento dos PlanMobs de outras cidades.

Vale ressaltar, ainda, que das 39 cidades descritas acima, 36 responderam à pesquisa realizada com os gestores públicos; ou seja, há uma forte correlação entre o que foi planejado e a visão dos gestores públicos sobre a gestão do TUC.

Sobre a forma dos documentos, uma vez que a PNMU não definiu um formato específico para os PlanMobs, documentos diversos foram coletados, como: relatórios finais e textos das leis municipais que instituíram os PlanMobs. Em sua maioria os documentos estavam em formatos de arquivos eletrônicos (pdf ou doc) e seguiam estruturas diferentes para apresentação do conteúdo.

Para a análise documental dos PlanMobs, procurou-se identificar a existência de uma seção específica para tratar do TUC ou de Logística Urbana, seguida de uma pesquisa simples da palavra 'Carga'. Após este filtro, foi feita uma análise de conteúdo, ou seja, “... um conjunto de técnicas de análise de comunicações" (Bardin 2009, p.31). Para este procedimento foi utilizada a "análise temática", que consistiu na busca de temas ou termos previamente definidos na literatura, que são pesquisados nos documentos. Logo, foi feito um pareamento que consiste em associar os dados recolhidos a um modelo teórico com a finalidade de compará-los" (Gil, 2002, p.90). Para tanto, foram utilizadas as palavras-chaves correspondentes às soluções de logística urbana apresentadas na Tabela 1. Por meio do uso do programa computacional QDA Miner 4 Lite, estes termos foram buscados nos documentos e posteriormente foram codificados e categorizados (Péladeau, 2004). Essa categorização permitiu avaliar a inserção do TUC nos planos de mobilidade urbana de cidades brasileiras.

\section{RESULTADOS E DISCUSSÃO}

Esta seção apresenta os resultados obtidos por meio do método de análise apresentado na seção anterior. 


\subsection{Pesquisa com gestores públicos}

As análises das 74 cidades participantes da survey foram divididas em dois grupos: cidades que não possuíam plano ou cujo plano estava em elaboração $(\mathrm{N}=25)$, e cidades que elaboraram os PlanMobs, aprovados ou não ( $\mathrm{N}=49)$. Observando a Figura 1, percebe-se que apenas a classe das cidades entre 250 mil e 500 mil habitantes, em sua maioria, não possuíam plano ou o documento estava em elaboração. É importante lembrar que a classe de cidade é uma nomenclatura utilizada no Caderno de Referência para Elaboração de Plano de Mobilidade Urbana (Brasil, 2015) e que também foi adotada neste artigo.

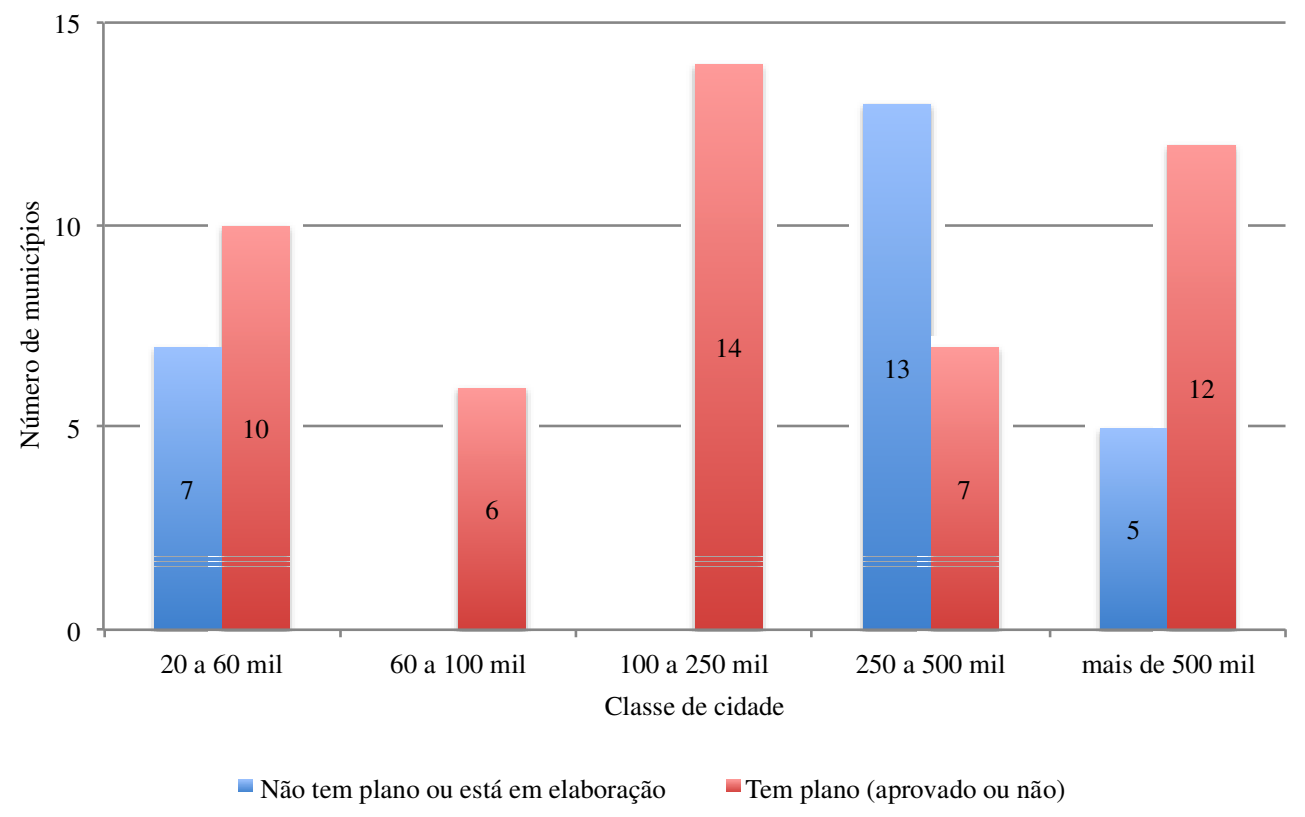

Figura 1. Número de cidades com PlanMobs por classes de cidade

Na Figura 1 é possível observar que existem cidades com mais de 500 mil habitantes que ainda não possuem plano, lembrando que foram analisados os planos daqueles municípios declarados até dezembro de 2017, com prazo de encerramento em julho de 2017 (Lei $\mathrm{n}^{\circ}$ 13.465). Tal fato chama a atenção, pois, por serem cidades de médio a grande porte, era esperado que já houvessem PlanMobs elaborados. Outro ponto a ser discutido é que os prazos referentes à elaboração dos PlanMobs pelos municípios foram postergados repetidas vezes pelo Governo Federal. Desta forma, revela-se que a parcela de municípios que já elaboraram os planos ainda é pequena, incluído várias cidades de grande porte no Brasil.

A Tabela 2 mostra que os responsáveis pelos planos de mobilidade urbana dentro dos órgãos municipais ocupam cargos da alta administração, em sua maioria diretores, gerentes e secretários. Este resultado indica que as propostas incluídas no plano de mobilidade têm potencial de implementação devido a uma possível influência política desses responsáveis.

Na Figura 2 são apresentadas as soluções para as cidades que já têm PlanMob, enquanto na Figura 3 são apresentadas as mesmas soluções para as cidades que ainda não têm PlanMob formalizado, segundo os gestores públicos. Observa-se que, em geral, as soluções de logística urbana reportadas são na maioria medidas restritivas e, portanto, pouco inovadoras. Esses resultados corroboram as afirmações de Bontempo et al. (2014), de que as práticas restritivas à circulação de veículos de cargas têm se tornado frequentes pelos governantes das cidades brasileiras. Além do mais, as medidas restritivas favorecem a fluidez dos automóveis e a 
mobilidade de pessoas, contrariando os objetivos da Política Nacional de Mobilidade Urbana, de mobilidade e acessibilidade também da carga (Oliveira et al., 2019). Por fim, muitas das soluções são copiadas de cidades para cidade (Dias et al., 2018), sem avaliação da realidade local.

Tabela 2 - Cargos dos respondentes

\begin{tabular}{lll}
\hline Tipo de Cargo & Tem PlanMob aprovado ou não & Sem PlanMob ou está em elaboração \\
\hline Arquiteto & $8,0 \%$ & $10,2 \%$ \\
Assessor & $8,0 \%$ & $12,2 \%$ \\
Chefe de setor/seção & $0,0 \%$ & $4,1 \%$ \\
Coordenador & $8,0 \%$ & $10,2 \%$ \\
Diretor & $36,0 \%$ & $16,3 \%$ \\
Gerente & $8,0 \%$ & $10,2 \%$ \\
Ouvidor & $0,0 \%$ & $2,0 \%$ \\
Secretário & $16,0 \%$ & $26,5 \%$ \\
Operacional & $12,0 \%$ & $6,1 \%$ \\
Engenheiro Civil & $4,0 \%$ & $2,0 \%$ \\
\hline
\end{tabular}

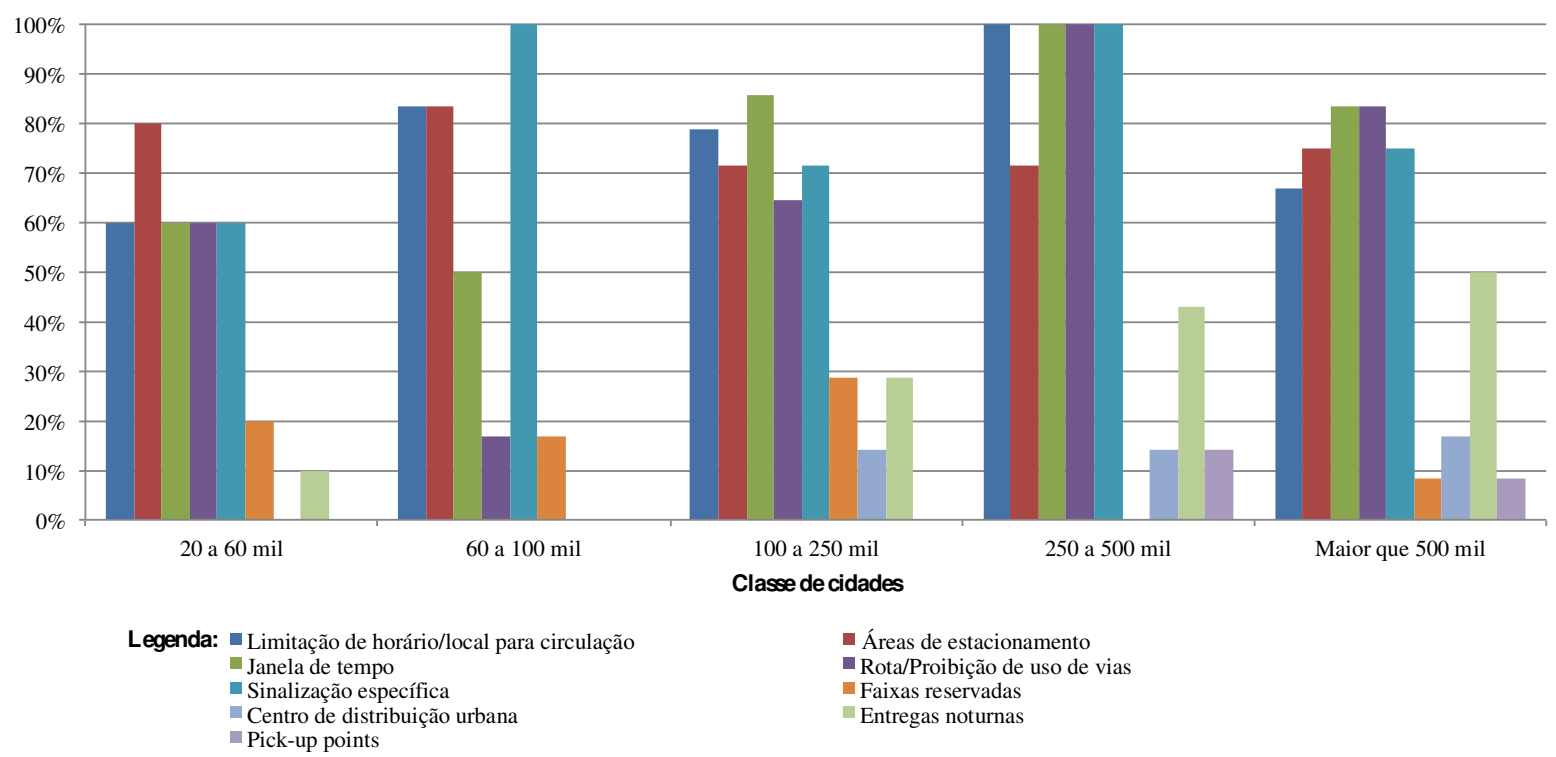

Figura 2. Soluções de logística urbana para os municípios com PlanMob

Contudo, as Figuras 2 e 3 apresentam soluções inovadoras para o contexto brasileiro. Por exemplo, existe um número crescente de cidades incluindo a entrega noturna nos planos de mobilidade. Além disso, à medida que a população aumenta, observa-se uma maior variedade de soluções de logística urbana mencionadas nos PlanMobs. Desta forma, pode-se confirmar um menor conhecimento de estratégias de gestão da carga urbana em cidades de pequeno porte, conforme apontado por Oliveira et al. (2019). Este conhecimento é fundamental para que a carga seja percebida como importante para a economia da cidade.

Na Tabela 3 é apresentada a estatística descritiva referente às percepções dos gestores sobre a importância do TUC para as cidades. Avaliou-se a importância considerando as cidades com e sem PlanMob. Observa-se que a mediana (Md) de todas as variáveis tiveram uma pontuação de 5 ou mais, indicando que pelo menos $50 \%$ tem concordância positiva em relação às variáveis consideradas. No geral, os resultados revelam uma falta de conhecimento da importância de um melhor planejamento da mobilidade da carga urbana, pois embora a grande maioria dos respondentes (cerca de 75\%, como mostra o terceiro quartil) concorde que há interesse no TUC e 
que o Plano de Mobilidade Urbana deva conter um plano de mobilidade urbana de carga, os gestores percebem que a movimentação urbana de cargas pode causar problemas no trânsito e que o transporte público de pessoas é mais importante que a movimentação de cargas.

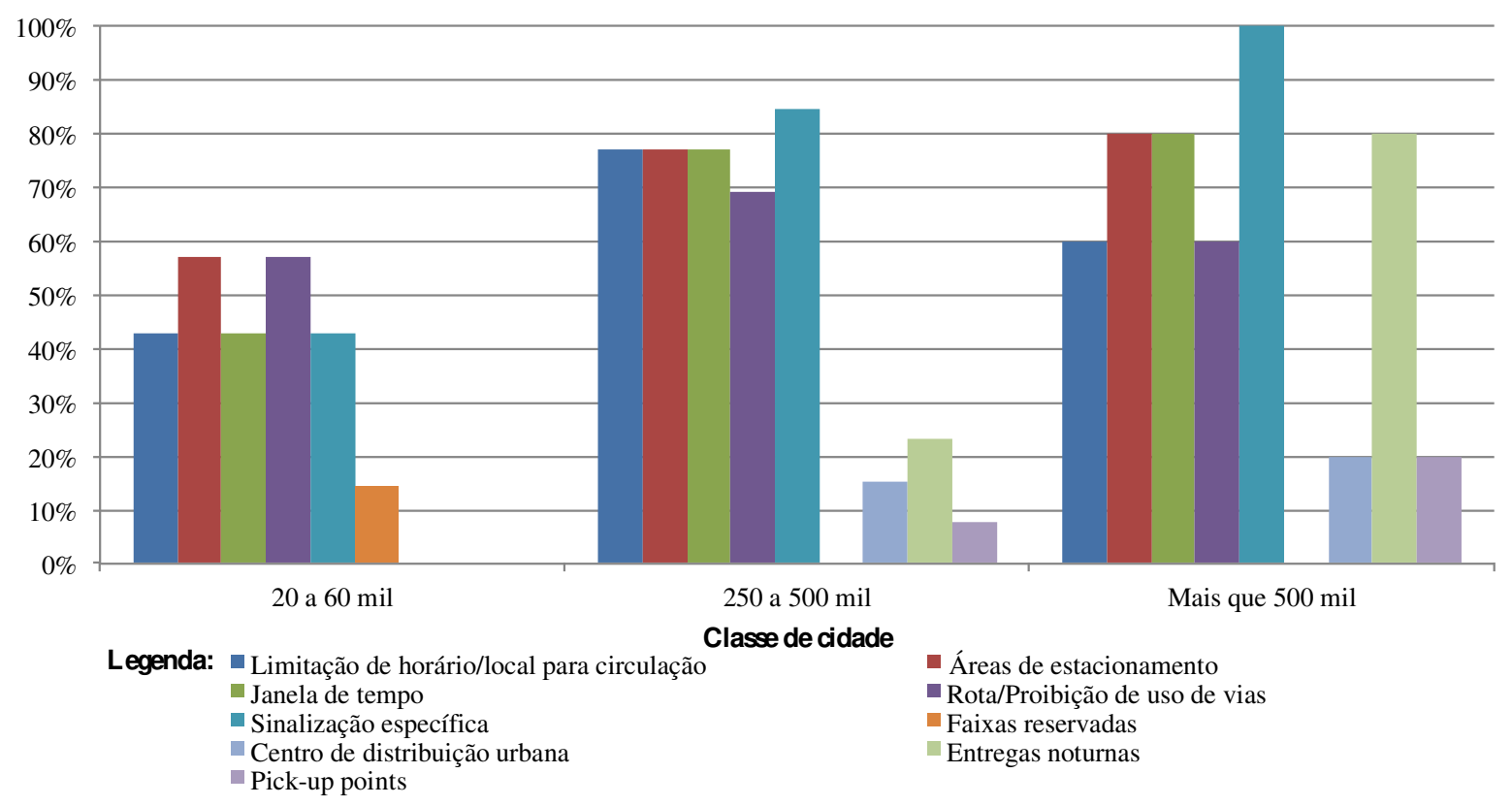

Figura 3. Soluções de logística urbana os municípios sem PlanMob

Tabela 3 - Estatística descritiva para a percepção dos agentes sobre TUC

\begin{tabular}{|c|c|c|c|c|c|c|}
\hline \multirow[t]{2}{*}{ Percepções da importância do TUC } & \multicolumn{3}{|c|}{$\begin{array}{l}\text { Não tem PlanMob/ } \\
\text { está em elaboração }\end{array}$} & \multicolumn{3}{|c|}{ Tem PlanMob aprovado ou não } \\
\hline & Md & 1Q & $3 Q$ & Md & 1Q & 3Q \\
\hline TUC é de interesse da prefeitura & 7 & 5 & 9 & 9 & 7 & 10 \\
\hline TUC causa problema & 9 & 8 & 10 & 10 & 8 & 10 \\
\hline Transporte de passageiro é mais importante do que o TUC & 8 & 7 & 10 & 8 & 7 & 10 \\
\hline Movimentação de automóvel é mais importante do que o TUC & 6 & 5 & 8 & 5 & 5 & 7 \\
\hline Conheço as melhores práticas de TUC & 5 & 3 & 6 & 5 & 4 & 7 \\
\hline Concordo que o PlanMob contenha TUC & 9 & 7 & 10 & 10 & 8 & 10 \\
\hline PlanMob é suficiente para adoção de boas práticas & 7 & 4 & 8 & 6 & 5 & 8 \\
\hline
\end{tabular}

Legenda: $\mathrm{Md}=$ Mediana, $1 \mathrm{Q}=$ Primeiro quartil, $3 \mathrm{Q}=$ Terceiro quartil

Por outro lado, observa-se que pelo menos a metade dos respondentes percebe a movimentação de veículos privados (automóveis) como mais importante do que a movimentação de cargas. Além disso, apenas $50 \%$ parece ter conhecimento das melhores práticas para a gestão do transporte urbano de carga e o mesmo percentual revela que os respondentes consideram o Plano de Mobilidade Urbana suficiente para a adoção de boas práticas para a movimentação de cargas. Esse resultado parece revelar pouco conhecimento ou valorização das soluções de logística urbana por parte dos gestores, independente da cidade ter elaborado um plano de mobilidade. Desta forma, pode-se concluir que existe pouco ou nenhum conhecimento sobre as soluções de logística urbana, apesar de estarem incluídas nos Planos de Mobilidade Urbana.

\subsection{Pesquisa Documental}

A pesquisa documental teve por objetivo analisar como os municípios brasileiros têm incorporado o TUC nos seus PlanMobs. Esta análise foi feita por meio do pareamento das soluções de logística urbana presentes nos PlanMobs de 39 cidades brasileiras, considerando a classificação 
proposta por Taniguchi e Thompson (2015). A Tabela 4 apresenta os resultados da frequência para cada tipo de gestão, método de gestão e soluções de logística urbana presentes nos PlanMobs, em números absolutos e percentuais. Em relação ao método de gestão, a gestão do fluxo de tráfego $(94,4 \%)$, de horário $(82,0 \%)$ e de estacionamento $(61,5 \%)$ são as mais comuns nos planos de mobilidade. Em relação às soluções de logística urbana, as que figuram com maior frequência nos planos de mobilidade analisados são: "janela de tempo para entrar nas cidades" (60\%), "rota para caminhões" (47,2\%), "áreas de carregamento / descarregamento nas ruas" (58,3\%) e "janela de tempo de entrega" (63,6\%).

Tabela 4 - Frequência das soluções de logísticas urbana

\begin{tabular}{|c|c|c|c|c|}
\hline Tipo de Gestão & Método de Gestão & Casos (\%) & Soluções de Logística Urbana & Casos (\%) \\
\hline \multirow{15}{*}{$\begin{array}{l}\text { Gestão } \\
\text { de } \\
\text { tráfego }\end{array}$} & \multirow{5}{*}{ Gestão de fluxo de trânsito } & \multirow{5}{*}{$37(94,9 \%)$} & Construção de anel viário & $11(28,2 \%)$ \\
\hline & & & Rota para caminhões & $18(46,1 \%)$ \\
\hline & & & Controle de acesso para as cidades & $7(17,9 \%)$ \\
\hline & & & Zona de baixa emissão & $1(2,6 \%)$ \\
\hline & & & $\begin{array}{l}\text { Fornecimento de informação de tráfego utilizando } \\
\text { Sistema Inteligente de Trânsito }\end{array}$ & 0 \\
\hline & \multirow{3}{*}{ Gestão de estacionamento } & \multirow{3}{*}{$24(61,5 \%)$} & Estacionamento exclusivo para veículo de carga & $6(15,4 \%)$ \\
\hline & & & Áreas de carga e descarga na via pública & $22(56,4 \%)$ \\
\hline & & & $\begin{array}{l}\text { Fornecimento de informação de estacionamento } \\
\text { utilizando Sistema Inteligente de Trânsito }\end{array}$ & 0 \\
\hline & \multirow{3}{*}{ Gestão de horário } & \multirow{3}{*}{$32(82,0 \%)$} & Entrega noturna & $6(6,6 \%)$ \\
\hline & & & Janela de tempo para entrar nas cidades & $25(64,1 \%)$ \\
\hline & & & Horário compartilhado entre caminhões e carros & $1(2,6 \%)$ \\
\hline & \multirow{4}{*}{ Gestão de veículo } & \multirow{4}{*}{$12(30,1 \%)$} & Veículos de baixa emissão de poluentes & $6(15,4 \%)$ \\
\hline & & & Otimização de rotas e escalas & 0 \\
\hline & & & Pedágio Urbano & $1(2,6 \%)$ \\
\hline & & & Controle de fator de carregamento & $5(12,8 \%)$ \\
\hline \multirow{4}{*}{$\begin{array}{l}\text { Melhoria no } \\
\text { modo de } \\
\text { transporte }\end{array}$} & \multirow{4}{*}{$\begin{array}{l}\text { Transporte cooperativo } \\
\text { Transporte intermodal } \\
\text { Co-modalidade do transporte de } \\
\text { carga }\end{array}$} & $9(23,1 \%)$ & Centros Urbanos de Consolidação & $9(23,1 \%)$ \\
\hline & & $5(12,8 \%)$ & Terminal intermodal & $5(12,8 \%)$ \\
\hline & & \multirow{2}{*}{0} & Pick-up Points & 0 \\
\hline & & & Veículos elétricos & 0 \\
\hline $\begin{array}{l}\text { Harmonia com } \\
\text { planos } \\
\text { diretores }\end{array}$ & Planejamento do uso do solo & $8(20,5 \%)$ & Restrições para localização de instalações logísticas & $8(20,5 \%)$ \\
\hline \multirow{4}{*}{ Outros } & Reconhecimento & $1(2,6 \%)$ & $\begin{array}{l}\text { Reconhecimento de transportadores com selo } \\
\text { verde }\end{array}$ & $1(2,6 \%)$ \\
\hline & $\begin{array}{l}\text { Sistemas de transportes } \\
\text { inovadores }\end{array}$ & 0 & Sistema de transporte de cargas subterrâneo & 0 \\
\hline & $\begin{array}{l}\text { Melhoria do código de } \\
\text { construção }\end{array}$ & $10(25,6 \%)$ & $\begin{array}{l}\text { Avaliação do tamanho de caminhões e estaciona- } \\
\text { mento no código de construção }\end{array}$ & $10(25,6 \%)$ \\
\hline & Organização & $7(18 \%)$ & Parcerias de qualidade de transporte de cargas & $7(17,9 \%)$ \\
\hline
\end{tabular}

Além disso, destaca-se praticamente a inexistência de soluções inovadoras no contexto brasileiro, como pedágio urbano, entrega noturna, zona de baixa emissão, pick-up points, utilização de veículos elétricos, dentre outros. Tais soluções de logística urbana são usuais em países europeus e americanos e ainda distantes no planejamento do transporte urbano de carga para as cidades brasileiras. Esses resultados confirmam os resultados anteriores de que, em geral, medidas restritivas são as mais usuais nos planos de mobilidade.

Na Figura 4 é apresentada a frequência de ocorrência das soluções de logística urbana nos planos de mobilidade. Ressalta-se novamente que as três primeiras soluções são medidas que impõem algum tipo de restrição ao transporte urbano de carga. 
Na Figura 5 é apresentada a frequência dos métodos de gestão nos planos de mobilidade. A "gestão de fluxo de trânsito", "gestão de horário" e a "gestão de estacionamento são os métodos comumente propostos nos Planos de Mobilidade. Na linha oposta, "sistemas de transportes inovadores", como por exemplo o crowdsourcing (Zheng, Li e Hou, 2011), e "co-modalidade do transporte de carga" não são citados nos PlanMobs.

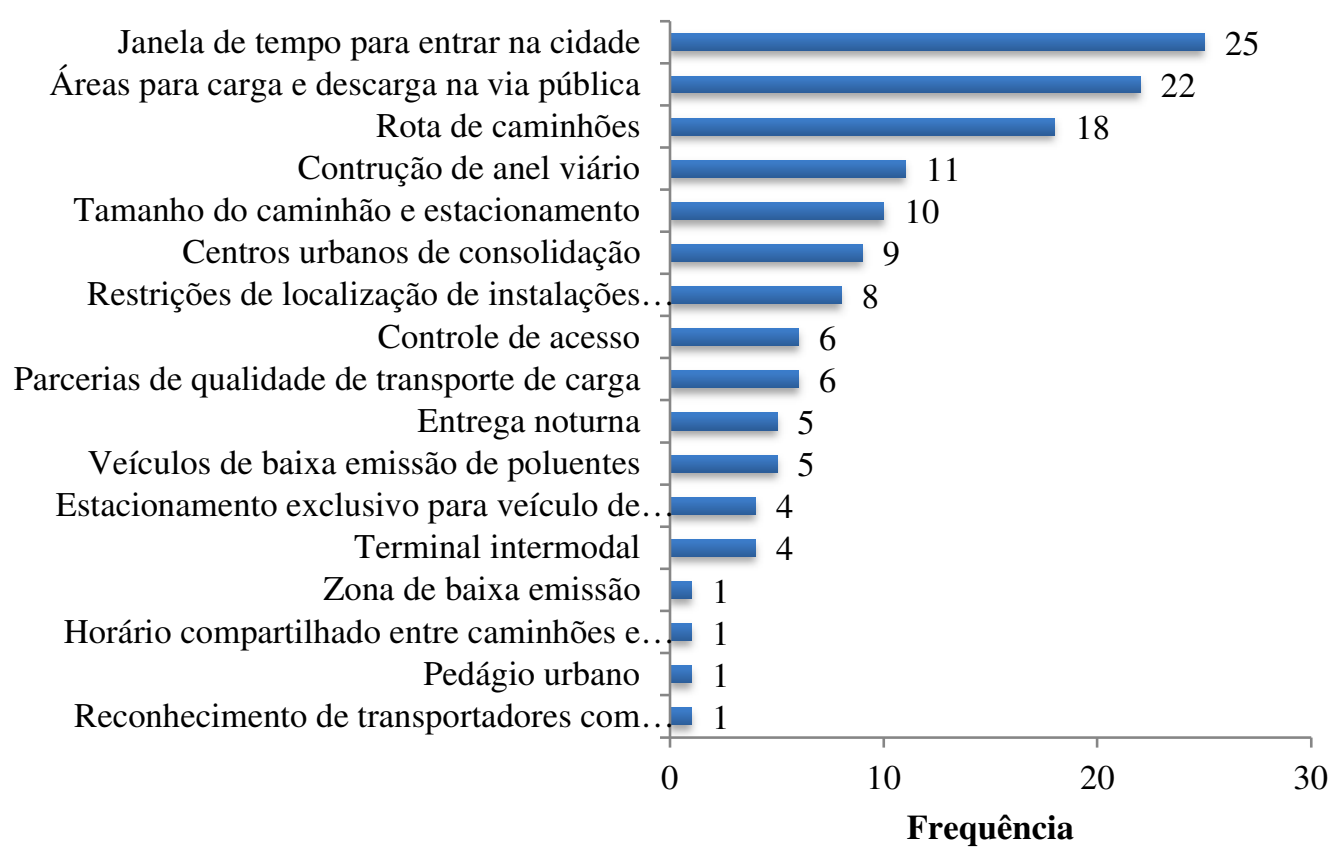

Figura 4. Frequência das soluções de logística urbana

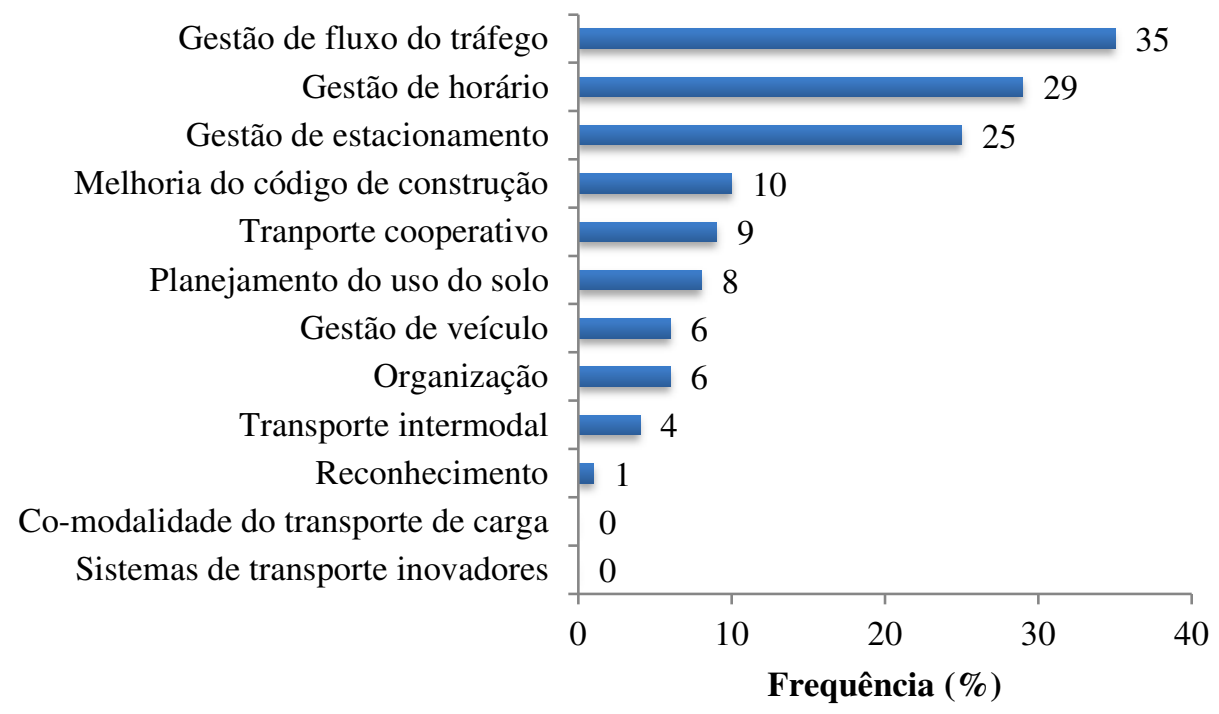

Figura 5. Frequência dos métodos de gestão de logística urbana

\subsection{Discussão dos resultados}

As soluções de logística urbana adotadas pelas cidades, independentemente de terem ou não terem elaborado PlanMobs, ou mesmo de sua classe populacional, são limitadas a um pequeno número de medidas, em geral, restritivas. As medidas restritivas estão alinhadas com o que está proposto no caderno de referência para elaboração de planos de mobilidade urbana. Segundo 
Brasil (2015), a estrutura mínima de um PlanMob, no que tange o transporte de carga, deve conter adoção de instrumentos legais (leis, decretos, portarias) para a limitação de horários e locais de circulação de veículos pesados, localização de áreas de estacionamento e determinação de horários para operação de carga e descarga na via pública. A "definição de rotas preferenciais e de vias de uso proibido", assim como "sinalização específica para veículos de carga (orientação e restrição)" são as soluções mais adotadas pelas cidades (Brasil, 2015, p.184). Desta forma, os resultados desta pesquisa permitem concluir que os municípios procuraram atender o conteúdo mínimo proposto por Brasil (2015).

Além do mais, essa conjuntura é coerente com a percepção dos gestores públicos respondentes, que atribuem uma maior importância ao transporte de pessoas por modos públicos ou privados. A priorização do transporte de pessoas é relatada na literatura por Dablanc (2007), Lindholm e Blinge (2014) e confirmada neste estudo também para o contexto brasileiro. A maioria dos gestores públicos respondentes concorda que o TUC causa problemas em suas cidades, que o TUC seja importante e que o PlanMob deve conter o planejamento do TUC, porém, as soluções planejadas, em sua maioria, repetem as práticas restritivas anteriormente mencionadas. De maneira a evidenciar as práticas planejadas mais frequentes, a Figura 6 apresenta o ranking das soluções de Logística Urbana (LU) reportadas, ordenadas de forma crescente, por frequência de casos e classe de cidade.

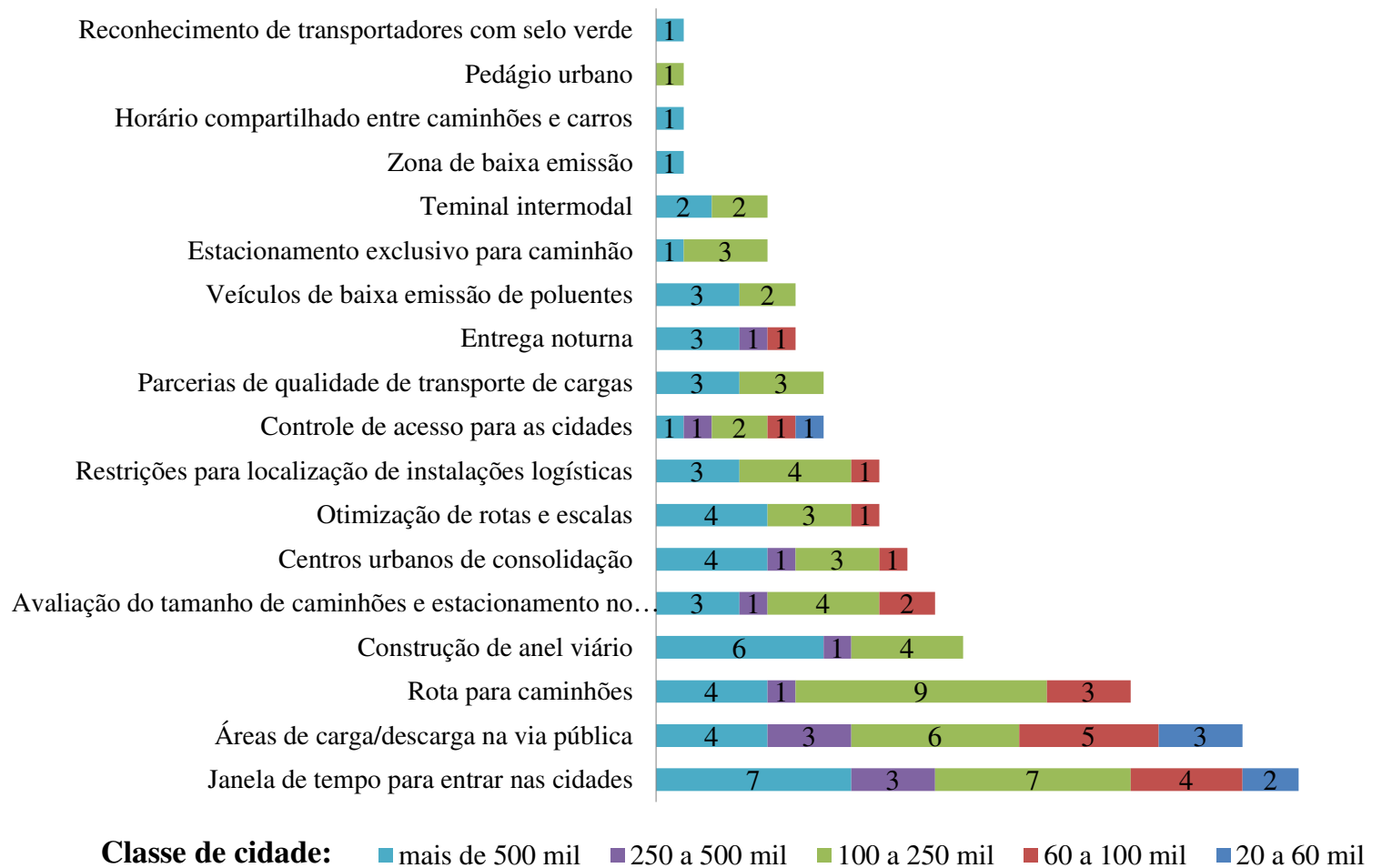

Figura 6. Distribuição das Soluções de Logística Urbana, por classe de cidades

O pareamento das soluções de LU incluídas nos PlanMobs, considerando a classificação proposta por Taniguchi e Thompson (2015), resultou nas frequências com que as soluções de LU estão presentes por PlanMob. Comparando as soluções planejadas (Figura 6), ou seja, aquelas que estão previstas no PlanMob, e as soluções adotadas, percebe-se que não há mudança prevista para o cenário planejado, visto que os padrões de frequências são muito similares e 
carecem da utilização das tecnologias da informação e comunicação. Ainda, as cidades com mais de 500 mil habitantes são aquelas que mais mostram diversificação de práticas planejadas, com 17 soluções, seguidas das cidades de 100 a 250 mil habitantes, com 15 soluções de LU. As cidades de 250 a 500 mil habitantes apresentam menor diversificação que as anteriores, com somente 8 soluções de LU. Com o menor número de práticas planejadas, estão as cidades de 60 a 100 mil habitantes com 3 soluções. As cidades com 250 a 500 mil habitantes revelaram-se fora da tendência de proporcionalidade do planejamento de mais soluções de LU em relação ao aumento da população.

Os resultados apresentados neste artigo apontam para uma direção preocupante no que tange ao planejamento do transporte urbano de carga. As soluções apontadas nos planos de mobilidade não estão relacionadas com os problemas identificados nas cidades brasileiras. 0 Brasil carece de dados sobre o transporte urbano de carga e a maioria dos planos de mobilidade elaborou diretrizes sem conhecer o problema. Desta forma, não se pode garantir a efetividade das soluções para os problemas relacionados ao TUC nessas cidades. Oliveira et al. (2019) já alertava para o desenvolvimento de políticas públicas dissociadas dos problemas do TUC. A falta de conhecimento do problema leva o poder público a replicar soluções sem avaliação da realidade local, conforme mencionado por Dias et al. (2018).

Desta forma, apesar de soluções de logística urbana estarem sendo contempladas nos planos de mobilidade urbana, pouco ou nada se sabe sobre a efetividade das mesmas, devido à falta de conhecimento do problema raiz. Como exemplo, muitas cidades replicam as restrições de acesso, tamanho e peso de veículos de carga apenas pelo fato da necessidade de incluir a carga nos planos de mobilidade. Para tanto, torna-se primordial o desenvolvimento de estratégias de coleta de dados para identificação dos problemas do TUC com base em dados e não apenas relatos. Pode-se citar o caso de Fortaleza que utilizou dados de notas fiscais para mapear os fluxos de carga na cidade (Bertoncini, 2019). Contudo, iniciativas como esta ainda são incipientes no Brasil.

Outro fato que é importante destacar é a integração da mobilidade de pessoas e mercadorias nos planos de mobilidade. Em geral, os capítulos que tratam da mobilidade da carga são isolados ou são relatórios individuais, sem conexão com a mobilidade de pessoas. Desta forma, a integração da mobilidade de pessoas e mercadorias ainda é um desafio no Brasil. Kiba-Janiak (2019) propõe um método holístico para que esta integração ocorra, baseado em estratégias de logística urbana que incluam objetivos abrangentes e de longo prazo, atividades relacionadas ao fluxo de mercadorias, pessoas e informações que podem ser efetivamente implementadas como resultado do compromisso obtido entre as partes interessadas. A implementação efetiva de estratégias de logística urbana deve resultar na melhoria da qualidade de vida dos habitantes das cidades (Kiba-Janiak, 2019). Desta forma, adaptar as estratégias propostas por Kiba-Janiak (2019) para a realidade brasileira pode ser um caminho para integrar a mobilidade e acessibilidade de pessoas e mercadorias.

\section{CONCLUSÃO}

Este artigo analisou como o transporte urbano de carga tem sido contemplado nos Planos de Mobilidade de cidades brasileiras. Os resultados indicam que as soluções de logística urbana estão sendo minimamente contempladas nos PlanMobs. Os conteúdos desses planos mostramse superficiais, com pouca informação a respeito das soluções de logística urbana, além de serem apresentados de forma dispersa. Verifica-se que as cidades, em geral, não fazem uso de 
soluções inovadoras e os gestores não percebem o transporte de carga como essencial para a sua gestão. As análises estatísticas mostraram que as soluções de LU adotadas pelas cidades brasileiras, independentemente do tamanho populacional, são limitadas em sua maioria a poucas soluções restritivas e sinalizações orientadoras relacionadas a estas restrições.

Os gestores públicos locais envolvidos na elaboração dos planos de mobilidade são principalmente secretários e diretores experientes que atuam em órgãos municipais ligados ao planejamento ou transporte, trânsito, ou mobilidade urbana. Os gestores concordam que o TUC é importante, mas percebem que ele gera problemas nas cidades, que o transporte público de pessoas é mais importante que o TUC e que a movimentação de automóveis é pouco mais importante que o TUC. Revelou-se que os gestores conhecem pouco as melhores práticas de TUC, mas concordam que o PlanMob deve conter um plano de TUC e que o PlanMob por si só é pouco suficiente para a adoção de boas práticas de TUC. Assim, existe baixa percepção de que o TUC deveria ser tratado como prioridade para mitigar os problemas de mobilidade, principalmente em regiões adensadas. Com isso, os PlanMobs parecem ser meramente relatórios que contemplam superficialmente o transporte de carga, para atender aos órgãos fiscalizadores e à lei vigente.

Conclui-se que apesar da PNMU prever o planejamento do TUC, este é tratado de forma incipiente pelos gestores das cidades brasileiras. Com poucas exceções, as cidades apenas repetem soluções historicamente adotadas, basicamente com foco na gestão do fluxo do tráfego do transporte público de pessoas, automóveis e restrição ao TUC. Portanto, os planos de mobilidade se limitam à citar a necessidade da gestão de transporte de carga ou apresentam planos mínimos que contemplam, principalmente: (a) limitação de horários e locais de circulação de veículos pesados; (b) localização de áreas de estacionamento e determinação de horários para operação de carga e descarga na via pública; (c) rotas alternativas para veículos de carga.

No entanto, os Planos não discutem os problemas gerados pelo TUC. Desta forma, pode-se concluir que as soluções de logística urbana propostas pelas cidades brasileiras, em geral, não tratam, ainda, o TUC como um problema que afeta a mobilidade urbana, o que dificulta o planejamento e o monitoramento das medidas adotadas e a sua efetividade. Dispor de dados para conhecer os problemas do TUC é um dos grandes desafios das cidades brasileiras para a elaboração de planos de mobilidade, que incluam a carga de maneira efetiva e eficiente.

Espera-se que os resultados desta pesquisa possam indicar para os gestores públicos as lacunas existentes para o planejamento do TUC e a possibilidade de uso de soluções de LU, aproveitando a oportunidade da obrigatoriedade legal imposta de PNMU, na elaboração de seus PlanMobs.

Reconhece-se que a pesquisa é limitada a uma parcela das cidades que participaram da survey e que houve dificuldade na obtenção dos PlanMobs, eventualmente bloqueados eletronicamente, impossibilitando o processo de análise. No entanto, pode-se dizer que a pesquisa revela o "status quo" da importância dada ao planejamento urbano de carga por uma boa parcela de cidades brasileiras localizadas na principal região econômica do país (região Sudeste), já que foi realizada uma análise com profundidade da percepção dos gestores e do conteúdo desses planos, além de comparar com aquelas cidades que ainda não têm PlanMobs. Vale ressaltar também, como limitação, que esta pesquisa apenas verifica se o TUC está sendo tratado e que tipo e método de gestão estão sendo considerados, mas não investiga os detalhes de cada plano e nem compara os seus conteúdos. 
Sugere-se para trabalhos futuros: (1) a ampliação da pesquisa com maior quantidade de cidades participantes, em virtude da ampliação do prazo legal para a elaboração dos PlanMobs para 2025; (2) a investigação das implicações da utilização das soluções de LU para a atratividade de atividades econômicas para as cidades; (3) a investigação específica com as cidades de classe de população entre 250 a 500 mil habitantes para procurar entender as diferenças de tendências com as cidades de outras classes populacionais e (4) a investigação sobre as implicações dos conjuntos de soluções de LU adotadas pelas cidades de destino para os custos dos transportes de cargas.

\subsection{Lições aprendidas}

- Transporte de carga parece não ser prioridade na elaboração dos PlanMobs das cidades brasileiras. Assim, o TUC é contemplado de forma secundária nos PlanMobs em comparação à mobilidade de pessoas. Além disso, as soluções de LU são contempladas nos PlanMobs de maneira superficial.

- As soluções de LU adotadas pelas cidades são majoritariamente restritivas e são similares àquelas em uso por cidades brasileiras de maior porte ou que têm melhor infraestrutura urbana, independentemente de possuírem ou não PlanMobs formalizados.

Cidades maiores apresentam maior diversidade de soluções de LU. No entanto, ainda parece existir uma barreira por parte do poder público na implementação de soluções alternativas para redução de externalidades como, por exemplo, zona de baixa emissão, pedágio urbano, entregas noturnas, pontos inteligentes de entrega. A maioria dessas medidas requer investimento em maior segurança local e maior envolvimento colaborativo de todos os agentes envolvidos.

\section{AGRADECIMENTOS}

Os autores agradecem ao CNPq, processo 3099172019-0, e a CAPES pelo financiamento desta pesquisa.

\section{REFERÊNCIAS}

Ballantyne, E. E. F., M. Lindnholm e A. Whiteing (2013) A comparative study of urban freight transport planning: Addressing stakeholder needs. Journal of Transport Geography, v. 32, p. 93-101. DOI: 10.1016/j.jtrangeo.2013.08.013

Bardin, L. (2009) Análise de conteúdo. Edições 70. Lisboa: Telles.

Bertoncini, B. V. (2019) 0 transporte urbano de carga em Fortaleza. In: Oliveira, L. K.; C. O. L. Nascimento; P. H. G. Pinto; O. R. Santos; L. S. F. P. Bracarense; R. L. M. Oliveira; S. A. Schreiner Junior; B. V. Bertoncini e Y. Yamashita (2019) A logística urbana no Brasil: a inserção do transporte urbano de mercadorias nas políticas públicas. Rio de Janeiro: Editora PoD, capítulo 4.

Bontempo, A.P., C. B. Cunha, D. A. Botter e H.T. Y. Yoshizaki (2014) Evaluating restrictions on the circulation of freight vehicles in Brazilian cities. Procedia Social and Behavioral Sciences,v. 125, p. 275-283. DOI:10.1016/j.sbspro.2014.01.1473.

Brasil (2011) Lei no 12.527 de 18 de novembro de 2011. Regula o acesso a informações previsto no inciso XXXIII do art. 5º, no inciso II do $§ 3^{\circ}$ do art. 37 e no $2^{\circ}$ o do art. 216 da Constituição Federal; altera a Lei no 8.112, de 11 de dezembro de 1990; revoga a Lei oㅡ 11.111, de 5 de maio de 2005, e dispositivos da Lei no 8.159, de 8 de janeiro de 1991; e dá outras providências. Disponível em: <http://www.planalto.gov.br/ccivil_03/_ato2011-2014/2011/lei/l12527.htm>. (Acesso em 26/08/2020).

Brasil (2012) Lei no 12.587 de 3 de janeiro de 2012. Institui as diretrizes da Política Nacional de Mobilidade Urbana; revoga dispositivos dos Decretos-Leis n⿳o s 3.326, de 3 de junho de 1941, e 5.405, de 13 de abril de 1943, da Consolidação das Leis do Trabalho (CLT), aprovada pelo Decreto-Lei no 5.452, de 1o de maio de 1943, e das Leis noํ 5.917, de 10 de setembro de 1973, e 6.261, de 14 de novembro de 1975; e dá outras providências. Disponível em: <http://www.planalto.gov.br/CCIVIL_03/_Ato2011-2014/2012/Lei/L12587.htm>. (Acesso em 26/08/2020).

Brasil (2018a) Medida provisória no 818, de 11 de janeiro de 2018. Altera a Lei n ⒔089, de 12 de janeiro de 2015, que ins-

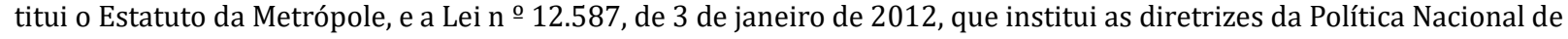
Mobilidade Urbana. Disponível em http://www.planalto.gov.br/ccivil_03/_Ato2015-2018/2018/Mpv/mpv818.htm. (Acesso em 17/03/2020).

Brasil (2018b) Lei no13.683/2018 de 19 de junho de 2018. Altera as Leis n o 13.089, de 12 de janeiro de 2015 (Estatuto da Metrópole), e 12.587, de 3 de janeiro de 2012, que institui as diretrizes da Política Nacional de Mobilidade Urbana. Disponível em http://www.planalto.gov.br/ccivil_03/_Ato2015-2018/2018/Lei/L13683.htm (Acesso em 17/03/2020). 
Brasil (2015) PlanMob - Caderno de Referência para Elaboração de Plano de Mobilidade Urbana. SeMob. Disponível em: < https://www.cidades.gov.br/images/stories/ArquivosSE/planmob.pdf >. (Acesso em 26/08/2020).

Browne, B., M. Lindholm e J. Allen (2015) Partnerships among Stakeholders. In: E. Taniguchi e Thompson, R.G. (Eds.) City Logistics Mapping The Future. (1a. Ed. pp. 1-12): CRC Press.

Carvalho, N. L. A., P. C. C. Ribeiro, C. García-Martos, C. G. Fernández, J. G. V. Vieira (2019) Urban distribution centres in historical cities from the perspective of residents, retailers and carriers. Research in Transportation Economics, v. 77, 100744. DOI: $10.1016 /$ j.retrec.2019.100744.

Cherrett, T., J. Allen, F. McLeod, S. Maynard, A. Hickford e M. Browne (2012) Understanding urban freight activity - key issues for freight planning. Journal of Transport Geography, v.24, p. 22-32. DOI: 10.1016/j.jtrangeo.2012.05.008.

Dablanc, L. (2007) Goods transport in large European cities: Difficult to organize, difficult to modernize. Transportation Research Part A, v. 41, n. 3, p. 280-285. DOI: 10.1016/j.tra.2006.05.005.

Hora, H. R. M., G. T. R. Monteiro e J. Arica (2010) Confiabilidade em questionários para qualidade: um estudo com o Coeficiente Alfa de Cronbach. Produto e Produção, v. 11, n. 2, p. 85-103. DOI: 10.22456/1983-8026.9321.

Denatran (2019) Percentagem de veículos, por tipo segundo o Brasil - DEZ/2019. Disponível em < https://antigo.infraestrutura.gov.br/images/Estatistica/RENAVAM/2019/Dezembro/Frota_Reg_UF-Tipo_Modelo_Dezembro_2019.xls>. (Acesso em 26/08/2020).

Dias, J. M., G. B. Sobanski, J. E. A R. Silva, L. K. Oliveira e J. G. V. Vieira (2018) Are Brazilian cities ready to develop an efficient urban freight mobility plan?.Urbe. Revista Brasileira de Gestão Urbana, v. 10, n.3, p.587-599. DOI: 10.1590/21753369.010.003.ao07.

Gatta, V. e E. Marcucci (2014) Urban freight transport and policy changes: Improving decision makers' awareness via an agent-specific approach. Transport Policy, v.36, p. 248-252. DOI: 10.1016/j.tranpol.2014.09.007.

Hair, J. F., W. C. Black, B. J. Babin, R. E. Anderson e R. L. Tatham (2009) Análise multivariada de dados. Porto Alegre: Bookman Editora.

IBGE (2010) Censo 2010. Disponível em: <http://censo2010.ibge.gov.br>. (Acesso em 20/07/2016).

Kiba-Janiak, M. (2017) Urban freight transport in city strategic planning. Research in Transportation Business \& Management, v. 24, p. 4-16. DOI: $10.1016 /$ j.rtbm.2017.05.003.

Kiba-Janiak, M (2019) Logistics in the cities'development strategies. Wroclaw: Wrocław University of Economics.

Lakshmanan, T. R. (2011) The broader economic consequences of transport infrastructure investments. Journal of transport geography, v.19, n.1, p.1-12. DOI: 10.1016/j.jtrangeo.2010.01.001.

Lima Neto, V. C. e E. P. Galindo (2013) Planos de mobilidade urbana: instrumento efetivo da política pública de mobilidade? Cadernos de arquitetura e urbanismo, Brasília. Disponível em: <https://www.ipea.gov.br/portal/images/stories/PDFs/TDs/td_2115.pdf>. (Acesso em 26/08/2020).

Lindholm, M. (2012) How local authority decision makers address freight transport in the urban area. Procedia Social and Behavioral Sciences, v.39, p.134-145. DOI: 10.1016/j.sbspro.2012.03.096.

Lindholm, M. (2013) Urban freight transport from a local authority perspective-a literature review. European Transport $\backslash$ Trasporti Europei, v. 54, n. 3, p. 1-37.

Lindholm, M. e M. Browne (2014) Local authority cooperation with urban freight stakeholders: A comparison of partnership approaches. Journal of Transport and Infrastructure Research, v. 13, p. 20-38. DOI: 10.18757/ejtir.2013.13.1.2986

Lindholm, M. e E. E. F. Ballantyne (2016) Introducing elements of due diligence in sustainable urban freight transport planning. Transportation Research Procedia, v. 12, p. 66-78. DOI: 10.1016/j.trpro.2016.02.04.

Lindholm, M. e S. Behrends (2012) Challenges in urban freight transport planning - a review in the Baltic Sea Region. Journal of Transport Geography, n.22, p.129-136. DOI: 10.1016/j.jtrangeo.2012.01.001.

Lindholm, M. e M. Blinge (2014) Assessing knowledge and awareness of the sustainable urban freight transport among Swedish local authority policy planners. Transport policy, v. 32, p. 124-131. DOI: 10.1016/j.tranpol.2014.01.004.

MCidades (2016) Levantamento sobre planos de mobilidade urbana. Ministério das Cidades. Disponível em: < https://www.cidades.gov.br/component/content/article?id=4398 >. (Acesso em 26/08/2020).

Oliveira, G. F. e L. K. Oliveira (2016) Stakeholder's Perceptions of City Logistics: An Exploratory Study in Brazil. Transportation Research Procedia, v. 12, p. 339-347. DOI: 10.1016/j.trpro.2016.02.070.

Oliveira, L. K. e E. D. Guerra (2014) A diagnosis methodology for urban goods distribution: A case study in Belo Horizonte City (Brazil). Procedia-Social and Behavioral Sciences, v. 125, p. 199-211. DOI: 10.1016/j.sbspro.2014.01.1467

Oliveira, L. K.; C. O. L. Nascimento; P. H. G. Pinto; O. R. Santos; L. S. F. P. Bracarense; R. L. M. Oliveira; S. A. Schreiner Junior; B. V. Bertoncini e Y. Yamashita (2019) A logística urbana no Brasil: a inserção do transporte urbano de mercadorias nas políticas públicas. Rio de Janeiro: Editora PoD.

Péladeau, N. (2004) QDA miner qualitative data analysis software, user's guide. Montreal: Provalis Research. 2004. Disponível em: <https://provalisresearch.com/uploads/QDA-Miner-5-User-Guide-V1.2.pdf>. (Acesso em 26/08/2020).

Quak, H. (2008) Sustainability of urban freight transport retail distribution and local regulations in cities. (Tese de doutorado), Erasmus Research Institute of Management (ERIM), Erasmus University Rotterdam, Rotterdam. Disponível em < https://repub.eur.nl/pub/11990/EPS2008124LIS9058921543Quak.pdf>. (Acesso em 26/08/2020).

Quak, H. (2011) Urban freight transport: the challenge of sustainability. In: C. Macharis e S. Melo (Eds.), City Distribution and Urban Freight Transport: Multiple Perspectives, (p. 37-55). Cheltenhan: Edward Elgar Publishing. 
Sanches Jr., E. Rutkowski e Lima Jr. O. F. (2009) A realidade das políticas públicas para a movimentação das cargas nas metrópoles brasileiras. In: XV Congreso Latino americano de Transporte Público y Urbano. Buenos Aires: CLATPU.

Silva, T. C. M. e K. R. C. C. Marins (2014) Discutindo o papel do transporte de carga no planejamento urbano: contextualização e comparativo conceitual. In: Anais do XXVIII Congresso de Pesquisa e Ensino em Transportes.

Stathopoulos, A.; E. Valeri e E. Marcucci (2012) Stakeholder reactions to urban freight policy innovation. Journal of Transport Geography, v. 22, p. 34-45. DOI: 10.1016/j.jtrangeo.2011.11.017

Taniguchi, E. (2015) Intelligent transport Systems in City Logistics. In: E. Taniguchi e R. G. Thompson (Eds.) City Logistics Mapping The Future. (p. 1-12.) Ed. Boca Raton: CRC Press.

Taniguchi, E. e R. G. Thompson (2015) Introduction. In: E. Taniguchi e R. G. Thompson (Eds.), City Logistics Mapping The Future. (p. 1-12) Boca Raton: CRC Press.

Un-Habitat (2013) Planning and design for sustainable urban mobility: Global report on human settlements. Disponível em: <http://unhabitat.org/books/planning-and-design-for-sustainable-urban-mobility-global-report-on-human-settlements2013>. (Acesso em 26/08/2020).

Wolfram, M. e R. Consult (2004) Expert working group on sustainable urban transport plans. Final Report,(Deliverable D4), Cologne, Germany: Rupprecht Consult. Dec 17.

Zheng, H.; D. Li e W. Hou (2011) Task design, motivation, and participation in crowdsourcing contests. International Journal of Electronic Commerce, 15(4), pp. 57-88. DOI: 10.2753/JEC1086-4415150402. 